\title{
Construção da participação comunitária para a prevenção de acidentes domésticos infantis
}

\author{
Constructing community involvement for the prevention of home accidents in children
}

Construcción de la participación comunitaria para prevenir accidentes domesticos infantiles

\author{
Justina Inês Brunetto Verruck Acker', Maria do Horto Fontoura Cartana' \\ 'Universidade Federal de Santa Catarina. Departamento de Enfermagem. Florianópolis, SC
}

Submissão: $24 / 01 / 2008$

Aprovação: 13/08/2008

\begin{abstract}
RESUMO
Introdução: Este artigo relata parte de um estudo cujo objetivo foi mobilizar a equipe do Programa de Saúde da Família para a construção da participação comunitária visando a prevenir acidentes domésticos de crianças menores de cinco anos, tendo como fundamento teórico as Sete Teses de Roberto Briceño-Léon. Metodologia: foi empregada a Pesquisa Convergente Assistencial com uma Equipe do Programa de Saúde da Família de uma cidade do interior do Rio Grande do Sul. Foram realizadas oficinas educativas com a equipe e posteriormente realizadas atividades educativas com famílias da comunidade. As informações foram coletadas por meio de observação e de entrevista coletiva, sendo realizada análise de conteúdo. Resultados: criação das ferramentas educativas: a música "A Lição do Sapeca", a dramatização da música, a dinâmica "O Que é isto?" e a dinâmica "Casa Simulada". Considerações: evidencia-se Que, com criatividade e congruência, a equipe de saúde desencadeou o processo de mobilização da comunidade para prevenir acidentes domésticos infantis.
\end{abstract}

Descritores: Participação comunitária; Educação em saúde; Acidentes domésticos.

\section{ABSTRACT}

Introduction: This paper reports part of a study whose aim was to mobilise a team for the Family Health Program to enable the citizen community involvement aiming at preventing domestic accidents for children under age five, through the theoretical framework of the Seven Theses by Roberto Briceño-Léon. Methodology: the Convergent Care Research was used with a Team for the Family Health Programme in a town in the country in Rio Grande do Sul. Educational workshops were first performed with the team and then educational activities were done with the families in the community. Data were collected through the observation, interview and content analysis. Results: Creation of four educational tools: the song 'A Lição do Sapeca', dramatisation of the song, the practice called 'O Que é isto?' and the practice called 'Casa Simulada'. Considerations: It is showed that through creativity and congruence the health team unleashed a process of the citizen community involvement for preventing child domestic accidents.

Descriptores: Comsumer participation; Health education; Accidents, home.

\section{RESUMEN}

Introducción: Este artículo relata parte de un estudio cuyo objetivo ha sido movilizar el grupo del Programa de Salud de la Familia para la construcción de la participación comunitaria para prevenir accidentes domésticos de niños menores de 5 años. La fundamentación teórica ha sido las Siete Tesis de Roberto Briceño-Léon. Metodología: Se ha usado la Investigación Convergente Asistencial con un grupo del Programa de Salud de la Familia de una ciudad del interior de Rio Grande do Sul. Se han realizado oficinas educativas con el grupo y después se han hecho actividades educativas con las familias de la comunidad. Las informaciones se han recogido a través de la observación y encuestas, y se ha usado el análisis de contenido. Resultados: Instauración de cuatro herramientas educativas: la canción "A Lição do Sapeca", la dramatización de la música, la dinámica ¿Qué es eso?, y la dinámica Casa Simulada. Consideraciones: Se evidencia Que con creatividad y congruencia el grupo de salud ha desencadenado el proceso de movilización de la comunidad para prevenir accidentes domésticos infantiles.

Descriptores: Participación comunitaria; Educación en salud; Accidentes domésticos. 


\section{INTRODUÇÃO}

Os acidentes domésticos com crianças menores de cinco anos são situações complexas e revelam grave problema de saúde pública ${ }^{(1)}$. Possivelmente ainda temos, no mundo, indicadores elevados de acidentes domiciliares infantis porque o acidente ainda é interpretado como obra do destino ou do acaso, ou ainda como algo comum nesta faixa etária. Sendo assim, além da identificação dos fatores envolvidos na ocorrência dos acidentes e do encaminhamento de suas conseqüências, é preciso propor e experimentar formas de promover saúde e prevenir acidentes domésticos infantis.

Acreditamos Que a abordagem familiar de prevenção, construída a partir da participação comunitária, pode ser eficaz no sentido de reduzir a ocorrência de acidentes ${ }^{(2)}$. Estudos nacionais e internacionais revelam Que aproximadamente $45 \%$ dos acidentes ocorrem no ambiente domiciliar, o Que contribui para aumentar significativamente as taxas de morbi-mortalidade de crianças $^{(3,4)}$.

Este estudo buscou construir uma proposta para mobilizar a equipe do Programa de Saúde da Família (PSF) para a construção da participação comunitária de famílias com crianças menores de cinco anos, visando a prevenir acidentes domésticos por meio da educação em saúde. Ao pensar na saúde, bem-estar e Qualidade de vida de famílias, a educação se evidencia como uma estratégia fundamental de intervenção, mas não deve ser pontual ou particular $^{(2-5)}$.

Defendemos a idéia de Que podemos (profissionais e famílias) promover a saúde da criança realizando prevenção de acidentes domésticos, com conhecimento adequado e tomando as devidas precauções de acordo com as necessidades de cada fase do crescimento e desenvolvimento da criança, especialmente se a atenção ambulatorial for permeada pela educação em saúde.

Por outro lado, há nos serviços de atenção básica à saúde distanciamento entre os profissionais de saúde e seus clientes, ou seja, ao cumprirem apenas as normas, as ações dos programas de saúde acabam nivelando as condutas e procedimentos gerais para resolver problemas de saúde, mas isto não garante cuidado Que atenda as necessidades das crianças $^{(6)}$.

Acredita-se Que a prevenção vai além da ótica epidemiológica, pois nesta pode deixar de se considerar comportamentos, subjetividades e necessidades individuais, familiares e sociais. Neste contexto há de se levar em conta a diversidade dos modos de vida, a variabilidade dos fatores envolvidos e a importância dada à saúde pelos atores. Compartilhar saberes com famílias e profissionais da saúde permite ir além da identificação das responsabilidades pelo acidente, busca-se incorporar formas educativas em saúde, sensatas e participativas e não coercivas ou punitivas. Desta forma, o pensar e o fazer prevenção de acidentes domésticos com foco centrado na família é uma prática educativa, e ao mesmo tempo, uma prática de cuidado transformadora em saúde.

\section{METODOLOGIA}

Trata-se de uma peseuisa de abordagem Qualitativa baseada no referencial metodológico da PesQuisa Convergente-Assistencial $(\mathrm{PCA})^{(7)}$ Que teve a participação ativa da equipe do Programa de Saúde da Família (PSF), composta por 11 profissionais: um médico, um enfermeiro, dois auxiliares de enfermagem, uma funcionária da farmácia, um secretário e cinco agentes comunitários de saúde.

O projeto foi aprovado pelo Comitê de Ética em Pesquisa da UNIVATES, $n^{0}$ 04/05, e os participantes assinaram o Termo de Consentimento Livre e Esclarecido, conforme previsto na Resolução $n^{0} 196 / 96^{(8)}$. Para preservar as identidades dos profissionais da saúde foram utilizados codinomes de pedras preciosas e para os familiares algarismos romanos. Após a apresentação e aprovação do projeto pelo Secretário da Saúde, previu-se a execução do mesmo em horário de trabalho, sendo Que a participação não implicava em prejuízos ao trabalhador. Também houve permissão para Que as falas fossem gravadas, mas o ambiente não favoreceu a sua execução. Por isso, as falas foram anotadas em diário de campo.

A coleta de dados foi realizada por meio de observação e

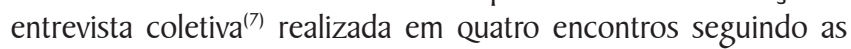
recomendações da técnica de grupo focal( ${ }^{(9)}$. Em cada encontro desenvolveu-se atividade específica, sendo o primeiro com a equipe de saúde, para as construções das ferramentas educativas, denominado primeira etapa da peseuisa. A segunda etapa foi composta por três encontros, Quando as ferramentas construídas foram aplicadas: a) um encontro com 18 crianças de uma turma da Escola de Educação Infantil - EMEI; b) um encontro com sete mães das mesmas crianças; c) um encontro cujo convite foi extensivo aos demais pais de crianças da referida escola, com a participação de 13 familiares.

A participação dos profissionais da equipe de saúde e dos pais foi voluntária e espontânea, não havendo exclusão de participantes da equipe de saúde porque todos se prontificaram a contribuir com o estudo. Os materiais educativos construídos pela equipe de saúde e utilizados nas atividades foram fotografados para facilitar a análise dos dados, conforme Apêndice B.

\section{RESULTADOS E DISCUSSÃO}

Os resultados aqui apresentados fazem parte da análise das informações obtidas na segunda fase da peseuisa. Nesta etapa a equipe de saúde utilizou o conhecimento e as ferramentas construídas e, a partir disso, implementou ações educativas com bases pedagógicas participativas e transformadoras. Este processo educativo ocorreu de forma progressiva, exigindo acolhimento, apoio, vontade, negociação, planejamento e envolvimento de ambas as partes (equipe de saúde, famílias), e tendo o apoio constante da pesquisadora.

Para a concretização das ações educativas pela equipe de saúde, foi muito importante acolher a idéia do outro, negociar alternativas para a prevenção, planejar ações educativas não tradicionais e avaliar continuamente os resultados. A equipe de saúde entendeu que é necessário motivar as famílias, pois se as famílias não participam fica mais difícil. Nós não vamos poder prevenir por eles (Ônix). Este relato contribuiu significativamente para desencadear reflexões sobre a importância da motivação da família em busca do cuidado da criança, especialmente a partir do momento em Que os participantes se apropriaram do referencial teórico ${ }^{(8)}$ proposto para subsidiar o estudo. As ações educativas tornaram-se concretas nos encontros com as crianças e com os pais, Quando os participantes se envolveram e apoiaram as decisões, já que os 
resultados dependiam da ação ou da não ação de cada pessoa. E é nos resultados das ações Que projetamos as expectativas, os interesses e os desafios das novas práticas educativas ${ }^{(10)}$.

Percebe-se Que a comunicação se estabeleceu de forma efetiva, tanto entre a pesquisadora e a equipe de saúde como entre a equipe de saúde e os demais participantes (crianças e pais), ficando claro Que Quanto mais as pessoas se conheciam mais se motivavam, especialmente porque não há aquele que sabe mais, e sim todos sabem coisas diferentes ${ }^{(10)}$. Esta forma de se comunicar possibilitou ampliar a interação, unificar o discurso em relação aos conceitos, entre eles: acidentes, prevenção, riscos, responsabilidades de cuidado.

Nos encontros a equipe de saúde apreendeu que o cuidado da criança é um compromisso social de cada cidadão, e não apenas da família. Como diz Topázio: "se eu vejo uma criança em perigo, eu tenho Que proteger. Eu não posso esperar pelos pais. Talvez eles estão ocupados com outras coisas".

Seguindo esta lógica, a equipe de saúde interagiu com as crianças e seus pais. Interagiu e mobilizou discussões, permitindo o aprofundamento teórico e a busca de significado a descobertas sobre a prevenção de acidentes infantis, conforme proposto na Pesquisa Convergente-Assistencial ${ }^{(7)}$. Para facilitar a interação, a equipe de saúde utilizou-se da criatividade das ferramentas educativas elaboradas, entre elas: a criação da música "A Lição do Sapeca”, a dramatização desta música, a criação da dinâmica da "Casa Simulada" e a dinâmica "O Que é isto?"

"Para Jaspe Verde, se a gente fizer uma coisa Que elas [as mães] gostam, daí elas vão contar para as outras, e daí na outra vez as mães vêm também". Este relato mostra que a equipe de saúde se comprometeu com o processo de mobilização para a construção de novas alternativas de educação em saúde, visando a movimentar a comunidade para a prevenção de acidentes domésticos. A seguir apresentamos a descrição sintética das atividades realizadas.

\section{Oficina com as Crianças}

Este encontro com as crianças foi realizado em Quatro momentos seQüenciais. No primeiro, a eQuipe de saúde recebeu as crianças em uma sala previamente organizada cantando a música "A Lição do Sapeca" (Apêndice A), Que trata dos principais tipos de acidentes domésticos (Quedas, Queimaduras, intoxicações).

No segundo momento, foi dramatizada a música - "A Lição do Sapeca", pelos membros da equipe, gerando muitos risos pelas crianças. Nesse momento ficou evidente Que as crianças interagiram muito com a equipe de saúde, a Qual todas as crianças já conheciam. As crianças estabeleceram a partir da dramatização associações significativas e concretas com as suas vivências, mostraram cicatrizes de Queimaduras e falaram sobre Quedas. Desta forma consideramos Que houve sintonia da criança com a atividade educativa, gerando possíveis indícios de aprendizados.

No terceiro momento a equipe de saúde desenvolveu uma dinâmica denominada "O Que é isto?", demonstrada na Figura 01 do Apêndice B. Utilizaram-se embalagens de produtos domissanitários, alimentos, balas e brinquedos de diferentes tamanhos, com o objetivo de compreender como as crianças percebem os riscos de acidentes. Nesta etapa as crianças também foram Questionadas sobre diferentes produtos e embalagens, sendo suas respostas posteriormente refletidas pela equipe de saúde em conjunto com as crianças.

Com essas atividades a equipe de saúde identificou que as crianças reconhecem os produtos Que estão contidos em embalagens originais, mas observou-se Que elas têm contato com produtos perigosos, do tipo: fósforo, pilhas e frascos de perfumes em spray. Manifestaram também intenso desejo de colocar na boca as coisas pequenas, especialmente aquelas que se assemelham com doces, podendo ser medicamentos ou mesmo pequenos objetos.

Analisando a atividade, a equipe de saúde concluiu que as crianças gostam de coisas diferentes, não necessariamente coloridas, e se tornam mais vulneráveis Quando estão com fome, isto porQue, entre tantos confetes coloridos Que constavam no pote Que o profissional mostrava para as crianças, a maioria delas pegou o único confete branco, aqui representado por um suposto medicamento, conforme demonstrado na Figura 02 do Apêndice B. A constatação foi possível porQue o encontro com as crianças aconteceu antes do horário do almoço.

Em relação à simulação de diversos produtos utilizados no domicílio, constata-se Que as crianças reconhecem o conteúdo dos frascos a partir da forma como os produtos são armazenados em suas casas. Neste caso, a maioria das crianças afirmou Que o frasco de vidro continha sal, Quando na verdade era açúcar ou, ainda, conforme assinalado pela equipe de saúde, poderia ser QualQuer outro produto Químico.

Quando as crianças tiveram contato com frascos de produtos domissanitários (Figura I), verbalizaram Que o frasco branco continha leite e no transparente água. Na verdade o frasco branco continha uma solução de farinha com água para simular desinfetante e o frasco transparente apenas água, simulando água sanitária. Estes resultados sinalizam Que a utilização de embalagens descartáveis para armazenar produto tóxico pode favorecer o risco de intoxicação exógena grave.

Com essa atividade evidencia-se Que as crianças com idades entre três e Quatro anos: preferem objetos em miniatura; desconhecem os perigos dos produtos domissanitários; o acondicionamento de produtos ou alimentos na embalagem original é mais seguro; não sabem diferenciar produtos pela cor ou pelo cheiro; estão tendo acesso a produtos de risco no domicílio (pilhas, fósforo, perfumes, etc).

No Quarto momento do encontro as crianças foram convidadas para retornar à sala de aula e interagiram com a professora, possibilitando refletir sobre a oficina, resultando em desenhos e dizeres sobre como cada uma delas associou a música à prevenção de acidentes domésticos. Ao serem Questionadas sobre o significado do seu desenho pela professora, explicaram: Não dá pra passar Quando o fio do ferro Que vai na luz tá no chão. Outra criança faz referência, ao comentar seu desenho: Não é prá mexer no fogão e na panela Quente, Que nem a menina mexeu e se Queimou. Isto também revela a livre circulação de crianças na cozinha de suas casas.

Os desenhos foram posteriormente analisados pela equipe de saúde, constatando-se que a atividade educativa realizada com as crianças gerou indícios de aprendizado. E, ao analisar a atividade como um todo, a equipe de saúde concluiu Que a criança estabelece associações significativas entre aQuilo Que vê e aQuilo Que vive no contexto familiar. Isto nos remete ao descrito na literatura sobre a importância dos exemplos das pessoas adultas e da influência Que 
a comunicação visual tem em relação aos seus modos de viver e prevenir acidentes domésticos ${ }^{(10)}$.

Os resultados da oficina com as crianças mostram Que ela é capaz de apreender Quando existe comunicação adeQuada entre aquele Que ensina e aquele Que aprende. A exemplo disso, ao serem estimuladas a refletir sobre a música: "A Lição do Sapeca", elas teceram relação com suas vivências anteriores. Estas reflexões possivelmente encaminham a criança para um amadurecimento Que pode efetivamente resultar em prevenção de acidentes domésticos ao longo de suas vidas. Isso demonstra Que devem existir construções contínuas e participativas com as crianças, buscando desenvolver sempre novas habilidades e competências para a prevenção de acidentes domésticos.

\section{Oficina com os Pais}

A oficina foi realizada com os pais das crianças Que estavam participando do projeto, sendo esta planejada e desenvolvida pela equipe de saúde com o objetivo de refletir sobre o papel dos pais na construção da prevenção de acidentes domésticos. Identificouse que a forma como a equipe recepcionou os pais foi fundamental para Que eles se sentissem estimulados a falarem sobre suas experiências vividas e sobre as possíveis estratégias de prevenção de acidentes domésticos. A preocupação em construir um ambiente acolhedor e informal faz parte do Que é recomendado na $P C A^{(7)}$ ao colocar Que a aproximação dos participantes pode facilitar a coleta de dados e a reflexão para a transformação do contexto vivido.

Nesta oficina os pais foram instigados pela equipe de saúde, desafiando o seu próprio saber, Que possivelmente encontrava-se latente ou distorcido sobre a prevenção de acidentes. As metas para melhorar as condições de vida ocorrem Quando a comunidade tem o direito e a responsabilidade de tomar decisões porque se sentem capacitadas para tal ${ }^{(10,1)}$. Entretanto, estes direito e responsabilidade, Quando exercitados na família, podem ser expandido para a sociedade. Pois é na família Que se estabelece o modelo de interação, assim como é nela Que são definidos objetivos comuns para a promoção da saúde de seus membros.

$\mathrm{Na}$ oficina com os pais, inicialmente foi desenvolvida a dinâmica "O que é isto?", ficando evidente Que os pais desconhecem como a criança interpreta o risco. Isso porQue a maioria das respostas apresentadas pelos pais foi contrária a das crianças, especialmente Quanto ao tamanho do brineuedo e objetos diferentes. As crianças demonstraram maior curiosidade pelas coisas bem pequenas, entre elas uma moto e uma bola em miniaturas. Já os pais disseram Que elas sentiram mais curiosidade para mexer com os brinquedos grandes e coloridos.

No segundo momento da oficina foi realizada a dinâmica da "Casa Simulada". Aqui a equipe de saúde mobilizou os pais para mobiliarem a casa, com os pequenos móveis e objetos contidos em um saco-surpresa, conforme demonstrado na Figura 4 do Apêndice B. Após a colocação de todas as mobílias e utensílios domésticos na Casa Simulada, os participantes puderam avaliar através das paredes vasadas como estavam as condições de segurança do domicílio e constataram Que a disposição dos móveis apresentava vários riscos de acidentes, entre eles: o botijão de gás próximo ao fogão, muitas coisas sobre a pia e sobre a mesa, bacia com água ao alcance das crianças e praticamente não foram utilizados os suportes e prateleiras existentes na cozinha. Da mesma forma, havia problemas de organização e de insegurança no Quarto e na área de serviço, conforme demonstrado na Figura 5 do Apêndice B.

Neste momento a equipe de saúde identificou que entre as mães uma ofereceu resistência à sugestão de troca dos móveis ou utensílios na Casa Simulada. Na medida em que esta mãe oferecia resistência, as demais também se pronunciavam em um movimento coletivo de mudanças Que progressivamente foi construindo consenso entre elas sobre a melhor disposição de objetos visando à prevenção de acidentes domésticos (demonstrado na Figura 6 do Apêndice B). Atentos a isto, a equipe de saúde interage com os pais e conseeüentemente mobiliza-os para concretizar medidas de prevenção. Aqui ocorre um movimento dialógico entre os participantes, mediado pela equipe de saúde, constatando-se que a criatividade dos pais e da equipe de saúde contribui para a segurança. A exemplo, Topázio diz: em uma casa de madeira muitas coisas podem ser penduradas e daí as crianças não pegam. Defendese que esta é uma estratégia simples e de baixo custo, mas que pode significar muitos benefícios para a criança.

A equipe de saúde, ao analisar os resultados, constatou Que é possível estabelecer a construção da participação comunitária por meio da educação em saúde, se o desafio for assumido coletivamente, desde o planejamento, organização e coordenação dos encontros, visando a atender ao principal objetivo e às expectativas dos envolvidos. Por meio das dinâmicas foram revelados indícios de aprendizados, sendo estes mais intensos e com maior grau de aprofundamento Quando os participantes interagiam nas reflexões. Possivelmente este aprendizado foi permeado pela comunicação efetiva estabelecida entre os profissionais de saúde e os participantes.

Evidencia-se também contribuições advindas do diálogo estabelecido entre a equipe de saúde e os pais, o Qual possibilitou identificar potencialidades individuais e coletivas, conduzindo para a expansão do conhecimento e a continuidade da proposta educativa em saúde. Esta expansão também resultou do grande número de Questionamentos e reflexões gerados a partir das dinâmicas citadas anteriormente, cujo objetivo foi investigar e educar.

O processo de mobilização desencadeado pela equipe de saúde se concretizou Qualitativamente, na medida em Que as relações foram sendo estabelecidas. Como diz Jaspe Rosa: "esta forma de educar é bem interessante, porQue a gente se envolve". Na medida em Que o grupo interagiu, possivelmente aprendeu e com isto descobriu potencialidades para a transformação, tanto na forma de perceber o ambiente domiciliar como na forma de conduzir os fatos e as subjetividades de cada participante. Quartzo afirmou: temos que respeitar as famílias. Não dá pra impor. Cada um vê o problema de um jeito.

No decorrer das atividades desenvolvidas pela equipe de saúde constatamos que cada participante pensa e age de forma única, é impregnado por subjetividades, crenças e valores Que possivelmente norteiam suas decisões, tanto para a ação como para a não ação individual, familiar e comunitária, aproximando-se do pensamento de Que o ser humano é único e tem liberdade para fazer suas escolhas $^{(12)}$, as Quais muitas vezes se refletem nas formas de expressão, nas atitudes e nas estratégias sociais e políticas Que adota. 
Por outro lado, percebe-se muito particularmente que não houve significativa participação de pais (homens) nas atividades desenvolvidas pela equipe de saúde. Diante desse contexto entendemos que isto é um desafio a ser vencido, o aumento da participação masculina em programas comunitários relacionados ao cuidado de crianças poderá contribuir para o aumento do valor familiar relativo às condições de segurança domiciliar, bem como aos cuidados a ela oferecidos.

Embora os resultados do estudo apontem Que o interesse pela reflexão-ação-reflexão sobre o tema tornou-se mais significativo Quando o participante tinha alguma experiência, cabe destacar Que geralmente esta se tratava de algo ruim e triste.

Percebe-se que os relatos dos participantes (a equipe de saúde e mães) estavam envoltos em sentimentos semelhantes, especialmente Quando os acidentes infantis mutilaram ou deixaram marcas em seus filhos - lesões físicas decorrentes de Queimaduras, intoxicações, entre outras. Essas experiências foram permeadas por saberes populares, saberes estes Que não foram ignorados, mas aprimorados durante o processo educativo em saúde. Sabese que a escuta dos relatos e a observação atenta da pesquisadora em relação ao silêncio de alguns participantes foi fundamental para o processo de mobilização da equipe de saúde. Quanto à escuta das vivências, foi adotada uma posição consciente, a de não procurar culpados para os acidentes. A posição exigiu não só uma atitude ativa de empatia com os relatos, mas também Que se dispusesse de tempo para as conversas informais Que normalmente aconteciam após as atividades planejadas, podendo esta ser utilizada como estratégia educativa em saúde.

Houve consenso de que esta realidade domiciliar pode ser transformada, se os pais ou cuidadores entenderem Que a casa pode não ser um local seguro, tornando-se necessário adotar medidas de segurança domiciliar, evitando descuidos e negligências no cuidado à criança. Sabe-se Que a insegurança domiciliar pode ser intensificada pela curiosidade da criança, especialmente Quando ela for atraída por cores, aromas e formatos. Evidenciou-se que a criança se torna mais vulnerável ao acidente doméstico Quando não recebe atenção necessária ou Quando os familiares desconhecem ou negligenciam a segurança no domicílio, de acordo com as características de cada fase de crescimento e desenvolvimento.

\section{CONSIDERAÇÕES FINAIS}

Os resultados do estudo apontam Que houve mobilização da equipe de saúde para a construção da participação comunitária, visando a prevenir acidentes domésticos com crianças menores de cinco anos, por meio da educação em saúde, tendo como base as "Sete Teses sobre Educação Sanitária para a Participação Comunitária”, de Roberto Briceño-León ${ }^{(10)}$.

A capacitação da equipe de saúde em relação ao fenômeno estudado e a construção e aplicação de estratégias educativas criativas são resultados concretos deste estudo. O marco referencial e a metodologia utilizada contribuíram para a construção do processo de mobilização da equipe do PSF, desencadeado a partir do comprometimento dos participantes com o projeto e da valorização do ser humano (a pesquisadora, as famílias e a equipe de saúde). O componente lúdico presente nas tecnologias educativas construídas pela equipe de saúde favoreceu o acolhimento dos sujeitos e de suas experiências, tornando-se possível compartilhar saberes sobre a prevenção de acidentes domésticos infantis.

A estratégia educativa desenvolvida pela equipe de saúde é contrária à rigidez dos programas com atos somente informativos, por serem muitas vezes excludentes e insuficientes, especialmente Quando neles estão inscritos apenas aspectos relacionados à incapacidade das famílias para a promoção de medidas de segurança no contexto domiciliar.

Então, supõe-se que a mobilização da equipe de saúde pode determinar nestas famílias, ao longo dos tempos, novas formas de cuidar. Possivelmente a capacitação e a motivação da equipe de saúde rompem barreiras impostas de forma prescritiva ou informativa e conscientizadoras, as Quais visam somente a modificar hábitos e comportamentos.

Conclui-se Que a família, Quando sensibilizada sobre a necessidade de segurança no ambiente domiciliar, faz reflexões pertinentes, compartilha saberes, constrói novas concepções, independente da condição econômica e social, especialmente Quando engajadas em um processo educativo em saúde. Neste caso, pensa-se Que a luta pela prevenção de acidentes domésticos revela-se uma tarefa imperativa e o êxito da prevenção depende do planejamento de medidas simples, da assimilação e aplicação da segurança domiciliar pelas famílias e comunidades.

Em suma, este estudo sinaliza Que as intervenções para a prevenção de acidentes domésticos devem ser construídas na base da sociedade (família, escola, unidades de saúde, igrejas), deixando de ser estratégia informativa e assumindo uma abordagem participativa e co-responsável, em Que as metas são estabelecidas pelos sujeitos do processo e o profissional da saúde assume o papel de mediador de reflexões e de ações de prevenção no contexto familiar.

\section{REFERÊNCIAS}

I. Ministério da Saúde (BR). Política nacional de redução da morbimortalidade por acidentes e violências: portaria MS/GM n· 737/GM, de 16 de maio de 200 I. Diário Oficial da União, 2001 maio 18.

2. Del Ciampo LA, Ricco RG, Mucillo G. Acidentes domésticos na infância na área de Vila Lobato, Ribeirão Preto-SP. Rev Pediatria 1997; 19(1): 38-42.

3. Acker IIBV. Acidentes domésticos: uma realidade familiar. In: Anais da Mostra de Ensino, Extensão e Pesquisa da UNIVATES.
2003. Lajeado (RS), Brasil. Lajeado: UNIVATES; 2003.

4. Pordeus AMI, Fraga MNO, Faco TPP. Ações de prevenção dos acidentes e violências em crianças e adolescentes, desenvolvidas no setor público de saúde de fortaleza, Ceará, Brasil. Cad Saúde Pública 2003; 19(4): I20 I-4.

5. Malveira EAP, Souza IEO. O cuidado de saúde à crianças: a posição prévia a partir das políticas públicas. Texto Contexto Enferm 1998; 7(2): 244-54.

6. Trentini M, Dias LPM. Pesquisa convergente-assistencial: um 
desenho Que une o fazer e o pensar na prática assistencial em saúde-enfermagem. 2a. ed. Florianópolis: Insular; 2004.

7. Ministério da Saúde (BR). Conselho de Saúde. Diretrizes e normas reguladoras de pesQuisa em seres humanos: resolução n. 196. Diário Oficial da União 1996 out 16.

8. Dall'Agnol CM, Trench MH. Grupos focais como estratégia metodológica em pesQuisas na enfermagem. Reva Gaúcha Enferm 1999; 20(1): 5-25.

9. Del Ciampo LA, Ricco RG. Acidentes na infância. Rev Pediatria 1996; 18(4): 193-7.
10. Briceño-León R. Siete tesis sobre la educación sanitária para la participación comunitária. Cad Saúde Pública 1996; I2(1): 7-30.

1 1. Bógus CM. Participação popular em saúde: formação política e desenvolvimento. São Paulo: Annablume/FAESP; 1998.

12. Carraro T. Estudo comparativo de conceitos e sua aplicação na enfermagem. In: Leopardi MT. Teorias em enfermagem: instrumentos para a prática. Florianópolis: FUFSC/Papa-Livros; 1999. p. 172-210.

\section{APÊNDICE A - Texto da música "A Lição do Sapeca"}

\section{A lição do Sapeca}

Joãozinho é um menino brincalhão correu, pulou Bateu a cabeça no chão Não escutou a mamãe

Ref: Aí, doeu, chorou, gritou, com tudo Isso aprendeu sua lição

Pedrinho, muito sem noção Abriu o cofrinho Engoliu um moedão Onde foi parar ... No barrigão.

Ref: Aí, doeu, chorou, gritou, com tudo Isso aprendeu sua lição

Gabriela foi na cozinha Puxou a panela e Queimou A cabecinha

Ref: Aí, doeu, chorou, gritou, com tudo Isso aprendeu sua lição

Maria encostou no fogão

Ele estava Quente Queimou o seu dedão

Ref: Aí, doeu, chorou, gritou, com tudo Isso aprendeu sua lição

Claudinha, tomou o remédio Da vózinha E agora está doente E ficou com dor na barriginha

Ref: Aí, doeu, chorou, gritou, com tudo 
APÊNDICE B: Fotos produzidas pela equipe de saúde do Bairro Santo André para demosnstrar os materiais utilizados nas oficinas com os pais e com as crianças para a prevenção de acidentes domésticos.

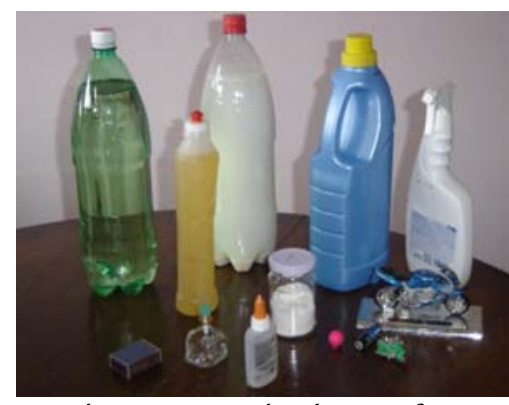

Figura 1: Fotos dos materiais utilizados em oficina com crianças

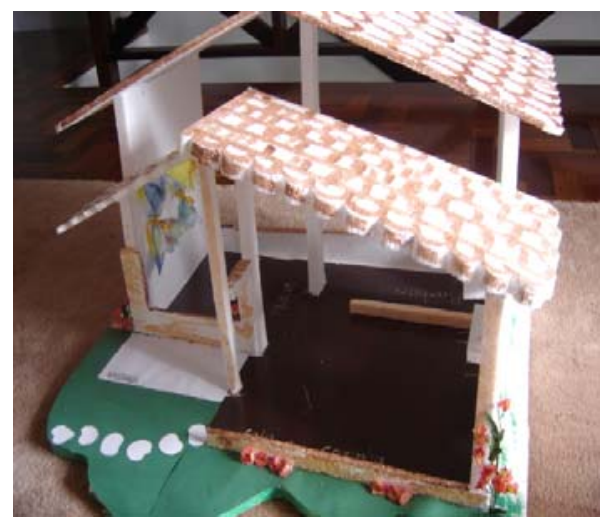

Figura 3: Foto da Casa Simulada

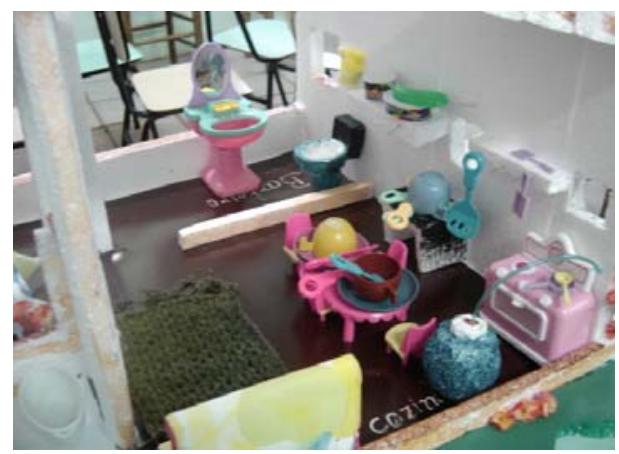

Figura 5: Foto demonstrando a colocação inicial dos móveis e utensílios

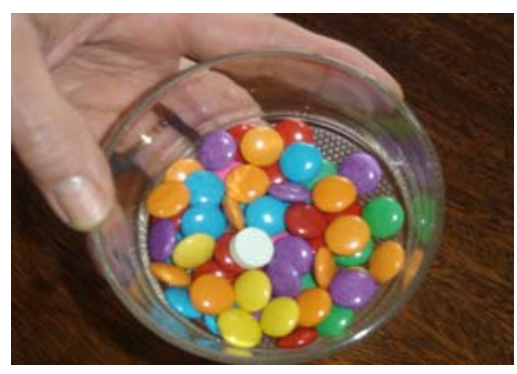

Figura 2: Fotos de balas utilizadas na oficina com crianças

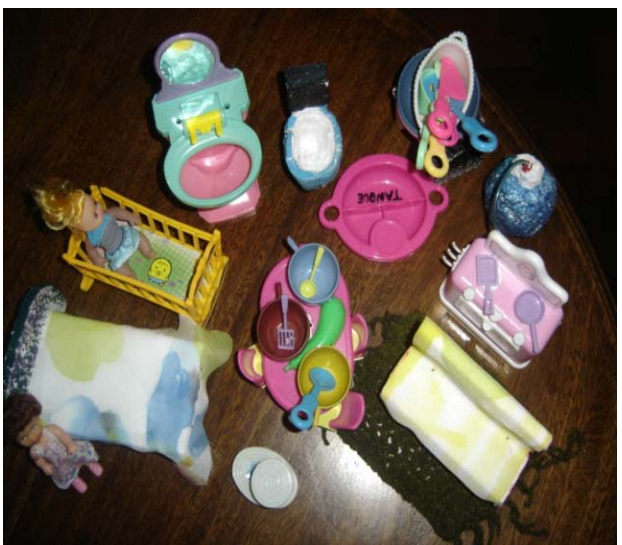

Figura 4: Móveis e utensílios colocados no saco surpresa

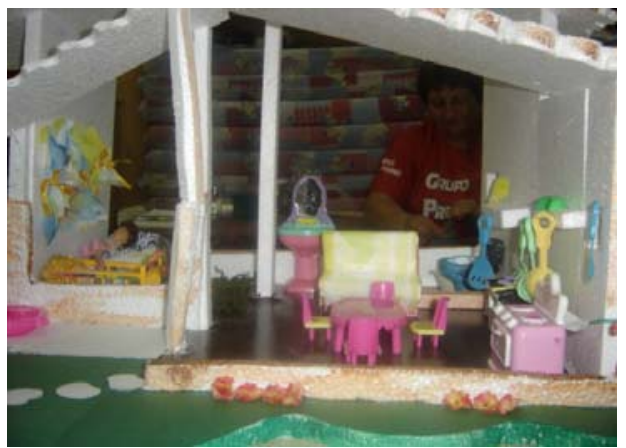

Figura 6: Foto demonstrando a colocação final dos móveis e utensílios 